\title{
POLLEN GRAIN MORPHOLOGY OF THREE SPECIES AND A VARIETY OF OCIMUM LINN. (LAMIACEAE) IN SOUTHWESTERN NIGERIA
}

\author{
O.O. Arogundade and O. Adedeji \\ Department of Botany, \\ Obafemi Awolowo University, \\ Ile-Ife, Nigeria.
}

\begin{abstract}
Pollen grains from fresh anthers of three species and a variety of Ocimum occurring in Southwestern Nigeria were collected and acetolysed. This was in an attempt to use the pollen characteristics to delimit, classify and trace probable evolutionary relationships among the taxa. The structural morphology of the pollen grains carried out with a light microscope is reported. Characters measured on the pollen grains were pollen diameter, pollen wall thickness, depth of colpi, distance between colpi and pore diameter. This was done with the aid of an ocular micrometer. Number of pores per pollen was counted. Pollen grain sizes of the species and the variety of

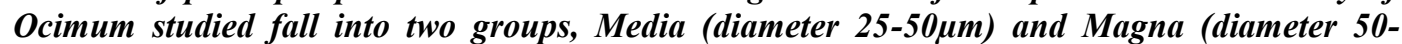
$100 \mu \mathrm{m})$. All the species and the variety had acolpate and hexacolpate pollen grains. Heptacolpate and octacolpate pollen grains which are advanced types of pollen grains were encountered in 0 . canum only. These advanced types of pollen grains are a mark of recent evolutionary development in the species.
\end{abstract}

Keywords: Ocimum, pollen grains, morphology, acetolysis, evolution

\section{INTRODUCTION}

The genus Ocimum Linn. belongs to the tribe Ocimeae, subfamily Nepetoidea, family Lamiaceae and the order Lamiales. About six species are currently recognized in West Africa and are generally distributed throughout the region as well as in parts of the world outside the African continent (Burkill, 1995). In Nigeria, five species of Ocimum have been reported which are distributed to both Southern and Northern Nigeria (Hutchinson and Dalziel, 1963). Three species and a variety of one of the species are found in Southwestern Nigeria.
These are: $O$. canum Sims, O. basilicum Linn., $O$. gratissimum Linn. and $O$. basilicum var. purpurascens Benth.

The genus Ocimum is one of the economically important groups of aromatic herbaceous plants extensively used in perfumery, flavouring and pharmaceutical products (Khosla, 1993). Many species of Ocimum have been grown by local people as medicinal plants, culinary herbs and insect controlling agents (Grayer et al., 1996).

Pollen characteristics have been used considerably in the taxonomy of angiosperms and can be applied in tracing the history of plant groups 
and species (Moore and Webb, 1978). Patel and Datta (1958) and Sowunmi (1973) are some of the researchers who have worked extensively on the morphology of pollen grains and have emphasized the significance of pollen architecture in phylogeny. The work of Akinwusi and Illoh (1996) on the pollen morphology of $\mathrm{Hi}$ biscus showed that the study of pollen grains (Palynology) provides useful data for the taxonomy of the genus. Adedeji (2005) traced the evolutionary relationships among three species of Emilia based on their pollen morphology. There is no reported work on the pollen morphology of the genus Ocimum in Nigeria. The aim of this study is therefore to use the characters of the pollen to delimit, classify and trace evolutionary relationships among the taxa of Ocimum in Southwestern Nigeria.

\section{MATERIALS AND METHODS Collection of Pollen grains}

Pollen grains from fresh anthers of flowers of the four taxa of Ocimum found largely in the
Southwestern part of Nigeria, namely, $O$. canum Sims, O. basilicum Linn., O. gratissimum Linn. and $O$. basilicum var. purpurascens Benth were collected across the region (Table 1).

\section{Acetolysis}

The collected pollen grains were acetolysed following the procedure of Erdtman (1960). The fresh anthers were placed in a centrifuge tube and macerated in $70 \%$ ethyl alcohol with a stirring rod. This dehydrated the pollen grains. These were then centrifuged at the speed of 5,000 revolutions per minute for fifteen minutes. The alcohol was poured off, glacial acetic acid was added and the mixture was centrifuged again at the same speed. Acetolysis mixture (sulphuric acid and acetic anhydride) was added next and the tube containing the pollen grains and the mixture was kept in water bath and heated from $70^{\circ} \mathrm{C}$ to boiling point. The mixture was then stirred with a glass rod and centrifuged again at the same speed as above,

Table 1: Provenances of the specimens studied

\begin{tabular}{|c|c|}
\hline Species & Area/Place of collection \\
\hline O. canum Sims & In front of a house, Ajebandele area, Ile-Ife, Osun State. \\
\hline O. canum Sims & In a garden, Line 3, Ooni Layout, Ajebandele, Ile-Ife, Osun State. \\
\hline O. canum Sims & In a garden, Road 9, O.A.U. Staff Quarters, Ile-Ife, Osun State. \\
\hline O. canum Sims & Along Road 7, Irepodun Street, Ile-Ife, Osun State. \\
\hline O. canum Sims & Seramo guest house junction, Eleyele, Ile-Ife, Osun State. \\
\hline O. canum Sims & Along the road, Agoare, Oyo State. \\
\hline O. basilicum Linn. & In a garden, Road 9, O.A.U. Staff Quarters, Ile-Ife, Osun State. \\
\hline O. basilicum Linn. & Isale Igbagbo street, Sepeteri, Oyo State. \\
\hline O. basilicum Linn. & In a garden, Line 3, Ooni Layout, Ajebandele, Ile-Ife, Osun State. \\
\hline O. basilicum Linn. & No 15, opposite Seramo guest house, Eleyele, Ile-Ife, Osun State. \\
\hline O. basilicum Linn. & Along the road, Owo, Ondo State. \\
\hline O. basilicum Linn. & In front of Flat 19, Omole Estate, Ile-Ife, Osun State. \\
\hline O. gratissimum Linn. & Old buka, O.A.U. Campus, Ile-Ife, Osun State. \\
\hline O. gratissimum Linn. & In a garden, Line 3, Ooni Layout, Ajebandele, Ile-Ife, Osun State. \\
\hline O. gratissimum Linn. & In a garden, Road 9, O.A.U. Staff Quarters, Ile-Ife, Osun State. \\
\hline O. gratissimum Linn. & Beside a house, Akinjagunla, Ondo, Ondo State. \\
\hline O. gratissimum Linn. & Ibadan - Oyo road, Ibadan, Oyo State. \\
\hline O. gratissimum Linn. & Erelu road, Oyo, Oyo State. \\
\hline O. gratissimum Linn. & Along the road, Ijebu-Ode, Ogun State. \\
\hline O. gratissimum Linn. & Along the road, Ipapo, Oyo State. \\
\hline O. gratissimum Linn. & Along the road, Oye, Ekiti State. \\
\hline O. basilicum var. purpurascens & By the roadside, Modakeke market, Ile-Ife, Osun State. \\
\hline O. basilicum var. purpurascens & In a garden, Road 9, O.A.U. Staff Quarters, Ile-Ife, Osun State. \\
\hline O. basilicum var. purpurascens & In a garden, Line 3, Ooni Layout, Ajebandele, Ile-Ife, Osun State. \\
\hline O. basilicum var. purpurascens & Behind Botany Dept., O.A.U., Ile-Ife, Osun State. \\
\hline
\end{tabular}


after which the acetolysis mixture was decanted and glacial acetic acid added. The mixture was then centrifuged again, distilled water added, followed by another centrifugation. The water was then decanted and the acetolysed pollen grains were mounted in dilute glycerin solution.

\section{Microscopy}

Acetolysed pollen grains were properly examined under the light microscope. Measurements of the diameter of pollen grain, wall thickness, depth of colpi, distance between apertures, and pore diameter as well as numbers of pores of 50 pollen grains were taken for each taxon with the aid of an ocular micrometer inserted in the eyepiece of the microscope. These measurements were later multiplied by the ocular constant with respect to the power under which they were taken. Photomicrographs of the acetolysed pollen grains were taken.

\section{Data Analysis}

The means of the data generated from the work were calculated. Statistical analyses include Analysis of Variance (ANOVA) and Duncan Multiple Range Test (DMRT) for significant differences among the species and the variety. A table illustrating the means of the pollen characters measured was prepared. Cluster diagram of the values was also made.

\section{RESULTS}

Generally, the pollen grains of the four taxa of Ocimum studied were spherical to ellipsoidal in shape. The two types of aperture, the colpi and the pores were present in the four taxa. Colpi were fissure-like or slit-like apertures, also known as furrows while pores were reticulate. All the species and the variety were polyporate. Furthermore, the pollens are reticulate, light yellow to yellowish in colour.

\section{O. canum}

The pollen types present were Acolpate (Plate 1 A), Monocolpate (Plate $1 \mathrm{G})$, Bicolpate (Plate 1 H), Pentacolpate (Plates 1 J, K \& L), Hexacolpate (Plates $2 \mathrm{~A}, \mathrm{~B}, \mathrm{C}$ ), Hexazonocolpate (Plate 1 E), Heptacolpate (Plates 3 A \& B), Octacolpate (Plates 3 C \& D), Figure 8 shape (Plates 1 I \& 3 F) and Ribbon-like shape (Plate 2 L). The mean diameter of the pollen grains was $79.01 \pm$ $1.09 \mu \mathrm{m}$ Table 2. The apertures were situated in both the polar and equatorial regions of the pollen grains.

\section{O. basilicum}

The pollen types present were Acolpate (Plate 1 A), Monocolpate (Plate $1 \mathrm{G})$, Bicolpate (Plate 1 $\mathrm{H})$, Hexacolpate and convex in shape (Plate 2 $\mathrm{G})$. The mean diameter of the pollen grains was $65.30 \pm 0.94 \mu \mathrm{m}$ Table 2). Colpi were situated in the polar region only while pores were situated both in the polar and equatorial regions of the pollen grains.

\section{O. gratissimum}

The pollen types present were Acolpate (Plate 1 C), Pentacolpate (Plate 2 D), Tetrazonocolpate (Plate 1 D), Hexazonocolpate and convex in shape (Plate $2 \mathrm{H} \& \mathrm{~J}$ ), Ribbon-like shape (Plate

Table 2: Quantitative characteristics and Duncan grouping of the four taxa of Ocimum studied based on the pollen grain attributes (means with the same letter are not significantly different).

\begin{tabular}{llccc}
\hline \multicolumn{1}{c}{ Parameters } & O. canum & O. basilicum & $\begin{array}{c}\text { O. basilicum var. } \\
\text { purpurascens }\end{array}$ & O. gratissimum \\
\hline Pollen diameter $(\mu \mathrm{m})$ & $(79.01 \pm 1.09) \mathrm{A}$ & $(65.30 \pm 0.94) \mathrm{B}$ & $(44.80 \pm 0.73) \mathrm{C}$ & $(49.45 \pm 0.49) \mathrm{D}$ \\
Pollen wall thickness $(\mu \mathrm{m})$ & $(5.55 \pm 0.15) \mathrm{A}$ & $(7.63 \pm 0.13) \mathrm{B}$ & $(4.38 \pm 0.12) \mathrm{C}$ & $(3.95 \pm 0.11) \mathrm{D}$ \\
Depth of colpi $(\mu \mathrm{m})$ & $(26.10 \pm 0.43) \mathrm{A}$ & $(20.58 \pm 0.52) \mathrm{B}$ & $(14.28 \pm 0.40) \mathrm{C}$ & $(13.04 \pm 0.38) \mathrm{D}$ \\
Distance between colpi $(\mu \mathrm{m})$ & $(26.49 \pm 0.32) \mathrm{A}$ & $(24.78 \pm 0.18) \mathrm{B}$ & $(13.15 \pm 0.13) \mathrm{C}$ & $(18.08 \pm 0.19) \mathrm{D}$ \\
Pore diameter $(\mu \mathrm{m})$ & $(7.37 \pm 0.13) \mathrm{A}$ & $(8.37 \pm 0.49) \mathrm{B}$ & $(5.02 \pm 0.11) \mathrm{C}$ & $(6.53 \pm 0.16) \mathrm{D}$ \\
Number of pores & $(57.82 \pm 1.40) \mathrm{A}$ & $(37.88 \pm 0.88) \mathrm{C}$ & $(46.58 \pm 1.48) \mathrm{B}$ & $(45.64 \pm 1.40) \mathrm{B}$ \\
\hline
\end{tabular}


$2 \mathrm{~K})$. The mean diameter of the pollen grains was $49.45 \pm 0.49 \mu \mathrm{m}$ Table 2 . The apertures were situated both in the polar and equatorial regions of the pollen grains.

\section{O. basilicum var. purpurascens}

The pollen types present were Acolpate (Plate 1 B), Tetrazonocolpate (Plate 1 D), Hexacolpate and convex in shape (Plate $2 \mathrm{E}, \mathrm{F} \& \mathrm{I}$ ). The mean diameter of the pollen grains was $44.80 \pm$ $0.73 \mu \mathrm{m}$ Table 2 . The apertures were situated in both the polar and equatorial regions of the pollen grains. The pollen diameter, the wall thickness, the depth of colpi, the distance between the colpi, the pore diameter, and the number of pores of the pollen grains are shown in Table 2.

The pollens quantitative characteristics of the species and the variety clustered into two main groups. $O$. basilicum var. purpurascens and $O$. gratissimum clustered together in the first main cluster while $O$. basilicum and $O$. canum clustered together in the second main cluster (Fig. $1)$.

\section{DISCUSSION}

The pollen grains of the Ocimum species and the variety studied looked similar, though there were some differences especially in $O$. canum where more colpi were encountered. The pollen grains of all the species and the variety were spherical to ellipsoid in shape.

The acolpate pollen grains were encountered in all the species and the variety studied. Monocolpate and bicolpate pollen grains were encountered occasionally in $O$. canum and $O$. basilicum. Pentacolpate pollen grains were encountered in O. canum and O. gratissimum. All

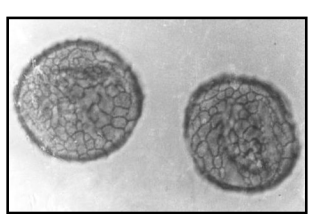

A

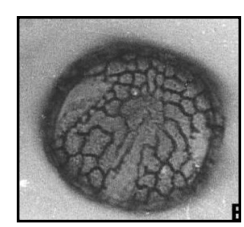

$\mathbf{E}$

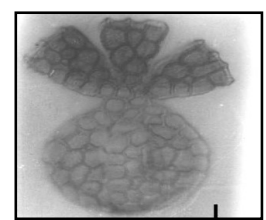

I

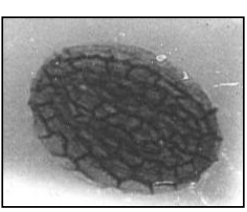

B

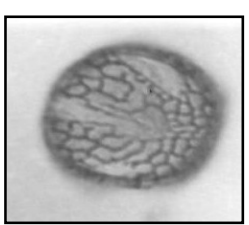

F

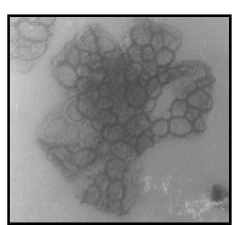

$\mathbf{J}$

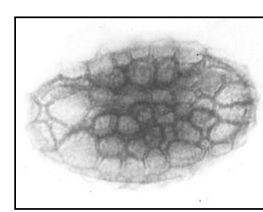

C

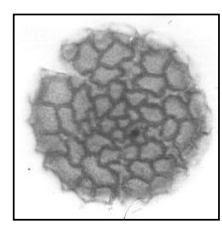

G

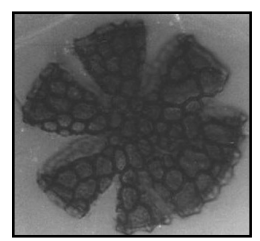

$\mathbf{K}$

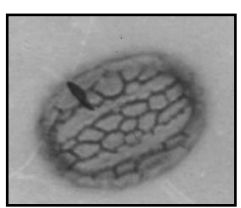

D

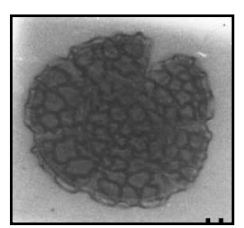

H

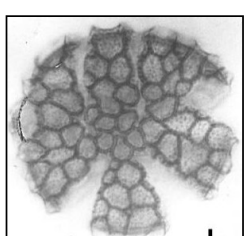

$\mathbf{L}$

Plate 1: Pollen grains of Ocimum species

A-C:Acolpate, D: Tetrazonocolpate, E and F: Hexazonocolpate, G: Monocolpate, H: Bicolpate

I: Tetracolpate (Figure 8 shape), J - L: Pentacolpate 


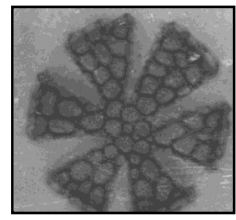

A

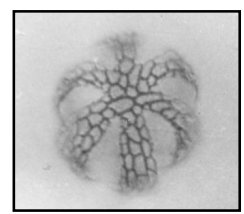

$\mathbf{E}$

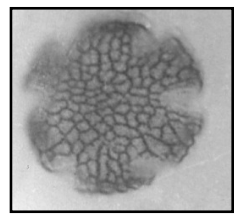

I

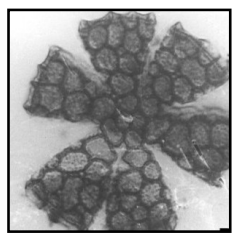

B

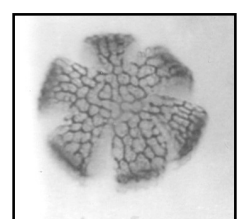

$\mathbf{F}$

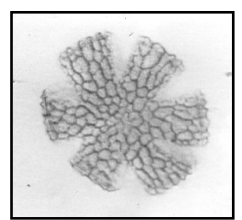

$\mathbf{J}$

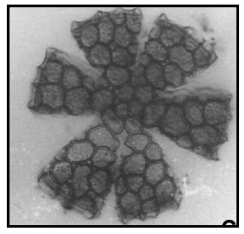

C

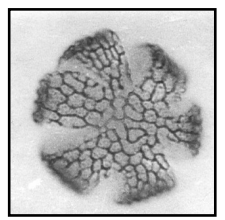

G

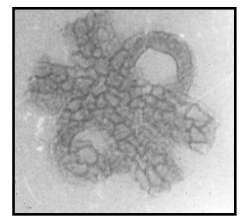

$\mathbf{K}$

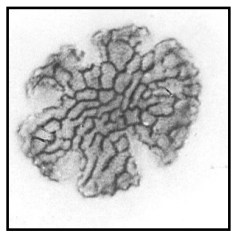

D

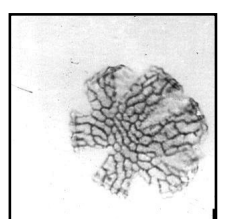

H

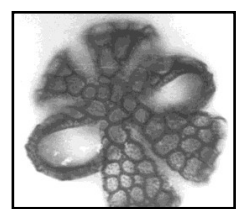

$\mathbf{L}$

$20 \mu \mathrm{m}$

Plate 2: Pollen grains of Ocimum species

A - C: Hexacolpate; D: Pentacolpate, E-J: Hexacolpate (Concave in Shape), K and L: Hexacolpate (Ribbon-like shape)
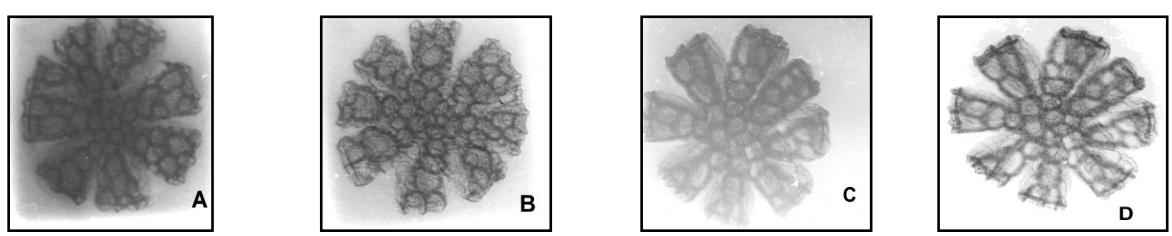

$20 \mu \mathrm{m}$

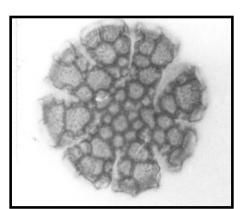

E

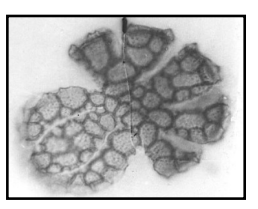

$\mathbf{F}$

Plate 3: Pollen grains of Ocimum species

A and B: Heptacolpate, C-E: Octacolpate, F: Octacolpate (Figure 8 shape) 


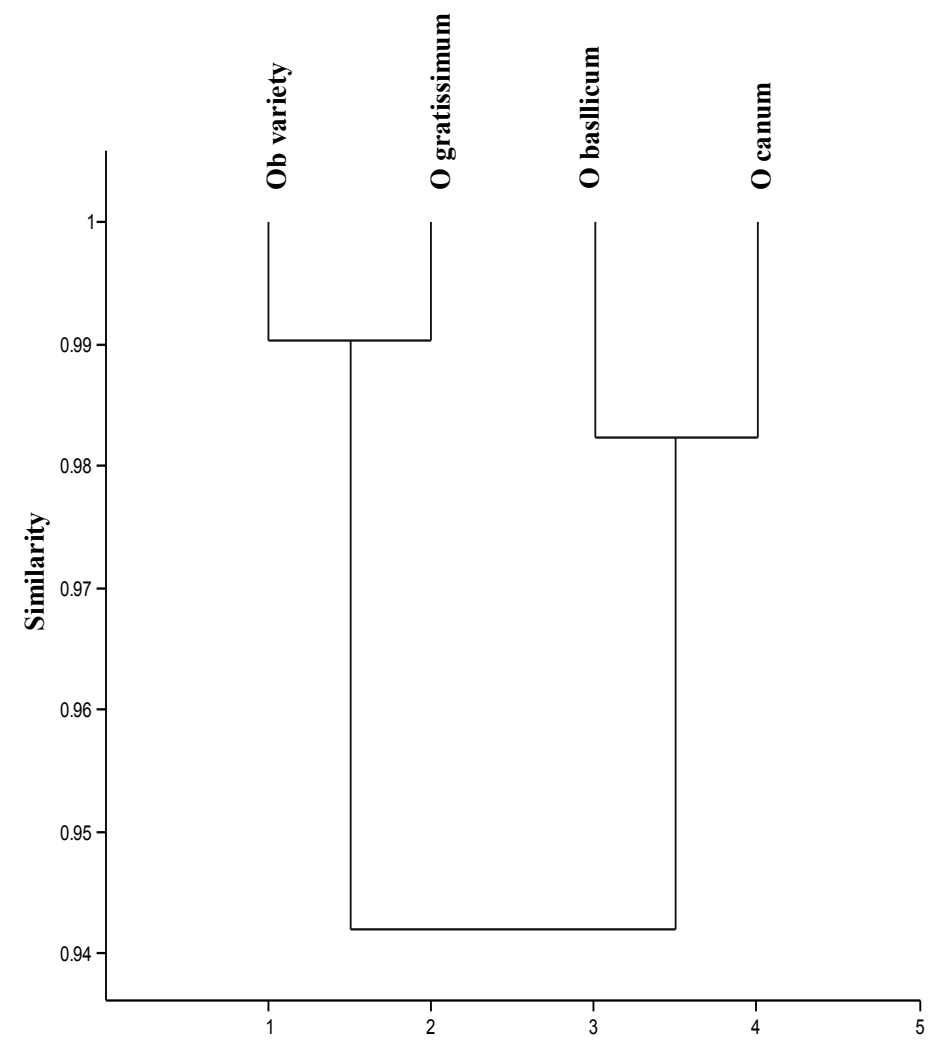

Fig. 1: Dendogram of the pollen grain attributes of the four taxa of Ocimum studied

the species and the variety had hexacolpate pollen grain. Heptacolpate and octacolpate pollen grains were encountered only in $O$. canum which separated this species from the others while the morphologically different pollen grains like the concave in shape were encountered in $O$. basilicum, $O$. gratissimum and $O$. basilicum var. purpurascens, the ribbon-like were encountered in $O$. canum, $O$. gratissimum and $O$. basilicum var. purpurascens and the figure 8 types were encountered in $O$. canum only which again delimits $O$. canum from the other species and the cultivar.

Tetrazonocolpate pollen grains with four colpi arranged in an equatorial zone were encountered in $O$. gratissimum and $O$. basilicum var. purpurascens while hexazonocolpate pollen grains with six colpi in an equatorial zone were encountered in $O$. canum only according to the descriptions of Moore and Webb (1978).

Heptacolpate and Octacolpate pollen grains, which are more advanced types of pollen, found to be occurring in $O$. canum were conspicuously absent in the other species and the variety. $O$. canum also has the largest size, highest colpi depth, highest number of pores and the largest distance between any pair of apertures. These further separate $O$. canum from the other species. The pollen grains of $O$. basilicum were distinct in having the thickest wall and the largest pore diameter size while $O$. gratissimum had the thinnest wall.

Analysis of Variance (ANOVA) reveals that there are significant differences within each attribute studied. Among the species and the variety, Duncan Multiple Range Test grouping of the Ocimum species and the variety based on 
the pollen grain attributes also reveal that there are significant differences among the pollen grain attributes of the species and the variety studied except in O. basilicum var. purpurascens and $O$. gratissimum where there is no significant difference in the number of pores.

Pollen grains have been classified into groups according to their sizes by Erdtman (1952) as Perminuta (diameter less than $10 \mu \mathrm{m})$, Minuta (diameter 10-25 $\mathrm{m}$ ), Media (diameter 25$50 \mu \mathrm{m}$ ), Magna (diameter 50-100 $\mu \mathrm{m}$ ), Permagna (diameter 100-200 $\mu \mathrm{m}$ ), Giganta (diameter greater than $200 \mu \mathrm{m}$ ). Based on this classification, the pollen grains of the genus Ocimum could be described as media (diameter

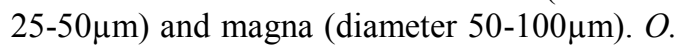
basilicum var. purpurascens and $O$. gratissimum belong to the group media while $O$. canum and $O$. basilicum belong to magna. In a similar study, Akinwusi and Illoh (1996) used pollen grain sizes to group some species of Hibiscus in Nigeria. O. basilicum var. purpurascens and $O$. gratissimum are more closely related here based on pollen grain attributes, since they clustered together at a higher similarity level than that of $O$. basilicum and $O$. canum.

Number of colpi on pollen grains has been a useful tool in tracing evolutionary relationship among the species of a genus. The advanced dicotyledons have more colpi than the primitive ones, with either a colpus (monocolpate) or none at all (acolpate) (Walker, 1976; Adedeji, 2005). It can thus be affirmed that the heptacolpate and octacolpate pollen grains observed only in $O$. canum is a mark of recent evolutionary development in the species.

\section{REFERENCES}

Adedeji, O. (2005). Pollen morphology of the three species of the genus Emilia Cass. (Asteraceae) from Nigeria. Thaiszia Journal of Botany 15: 1 - 9.

Akinwusi, O. and Illoh, H.C. (1996). Pollen grain morphology of some species of $H i$ - biscus Linn. Nigerian Journal of Botany 9: $9-14$.

Burkill, H.M. (1995). The Useful Plants of West Tropical Africa. $2^{\text {nd }}$ Edition. Royal Botanic Gardens, Kew. Vol. 3: $19-27$.

Erdtman, G. (1952). Pollen morphology and Plant taxonomy of Angiosperms. Almqvist and Wiksell, Stockholm, p. 539.

Erdtman, G. 1960. The acetolysis method in a revised description. Svensk Botanisk Tidskrift, Lund 54(4): 561-564.

Grayer, R. J., Goeffrey, C.K., Goldstone, F.J., Bryan, E.S., Paton, A. and Putievsky, E. (1996). Infraspecific taxonomy and essential oil chemotypes in sweet basil, Ocimum basilicum. Phytochemistry 43(5): 1033 1039.

Hutchinson, J. and Dalziel, J.M. (1963). Flora of West Tropical Africa. Second Edition. Vol. II. Crown Agents London. p. 450.

Khosla, M. K. (1993). Study on interrelationship, phylogeny and evolutionary tendencies in genus Ocimum. Journal of Plant Anatomy and Morphology. 6 (1): 93 $-106$.

Moore, P.D. and Webb, J.A. (1978). An Illustrated Guide to Pollen Analysis. Hodder and Stoughton, London. p. 133

Patel, G.I. and Datta, R.M. (1958). Pollen grain studies in various types of Corchorus olitorius L., C. capsularis L. and some other species of Corchorus. Grana Palynological I: $18-24$.

Sowunmi, M.A. (1973). Pollen grains of Nigerian Plants. Grana 13: 145 - 186.

Walker, I.W. (1976). Evolution of exine structure in the pollen of primitive angiosperms. 